\title{
ESTUDIO DE LA RECENSIO EN LA NOVELA EL MAESTRO DE ESCUELA DEL ESCRITOR COLOMBIANO FERNANDO GONZÁLEZ*
}

\author{
Study of THE RECENSIO In THE NOVEL $E_{L}$ \\ MAESTRO DE ESCUELA BY THE COLOMBIAN \\ writer Fernando González
}

\begin{abstract}
* Este artículo es resultado parcial del proyecto de investigación número 2018-23074 "Estudio previo y edición crítica de la obra completa de Fernando González. Primera etapa", financiado por el Comité para el Desarrollo de la Investigación - CoDI- de la Universidad de Antioquia, y contó con el apoyo del programa de Estrategia de Sostenibilidad 20202021 del grupo de investigación Estudios Literarios, otorgado por la Vicerrectoría de Investigación de la Universidad de Antioquia. UdeA, Cl 70 \# 52-21, Medellín - Colombia.

Cómo citar este artículo: CarvajalCordoba, E. y Gallego Duque, F. (2021). Estudio de la recensio en la novela $E l$ maestro de escuela del escritor colombiano Fernando González. Estudios de Literatura Colombiana 48, pp. 225-244. DOI: https:// doi.org/10.17533/udea.elc.n48a14

1 https://orcid.org/0000-0002-0339-3562 edwin.carvajal@udea.edu.co Universidad de Antioquia, Colombia

2 https://orcid.org/0000-0002-4694-3499 felix.gallego@udea.edu.co

Universidad de Antioquia, Colombia
\end{abstract}

Editores: Andrés Vergara Aguirre, Christian Benavides Martínez, Valentina Noreña Gómez

Recibido: 15.08 .2020

Aprobado: 05.11.2020

Publicado: 18.12 .2020

Copyright: (2021 Estudios de Literatura Colombiana. Este es un artículo de acceso abierto distribuido bajo los términos de la Licencia Creative Commons AtribuciónNo comercial - Compartir igual 4.0 Internacional
Edwin A. Carvajal-Cordoba, ${ }^{1}$ Félix Antonio Gallego Duque ${ }^{2}$

Resumen: Este artículo de investigación presenta el análisis de la recensio en la novela El maestro de escuela (1941) del escritor Fernando González. Este estudio se realiza desde el enfoque teórico de la crítica textual, específicamente desde su primera etapa, con el objetivo de restituir la novela en edición crítica de acuerdo con la última voluntad del escritor. En este sentido, se abordarán todos los componentes de la primera etapa de la crítica textual, para aportar a un mejor conocimiento de las transformaciones que han experimentado los distintos testimonios de El maestro de escuela, en su historia de transmisión textual.

Palabras clave: Crítica textual; Edición crítica; Literatura colombiana, El maestro de escuela, Fernando González.

Abstract: This research article presents the analysis of the recensio in the novel El maestro de escuela (1941) by the writer Fernando González. This study is carried out from the theoretical approach of textual criticism, specifically from its first stage, with the aim of restoring the novel in a critical edition in accordance with the last will of the writer. In this sense, all the components of the first stage of textual criticism will be addressed, in order to contribute to a better understanding of the transformations that the different testimonies of El maestro de escuela have undergone, in its history of textual transmission.

Keywords: Textual criticism; Critical editing; Colombian literature, El maestro de escuela, Fernando González. 
Un texto es todo aquel mensaje verbal que se transmite a través de la escritura. Quien dice escritura dice error, puesto que quien escribe, tanto si se trata de un texto original - una carta, por ejemplo - como de una copia, tiene que llevar a cabo un proceso en apariencia simple pero que en la realidad reviste una gran complejidad al tratarse de varias operaciones psicológicas y mecánicas o, si se prefiere, psicologicomecánicas

(Blecua, 2012, p.19).

\section{Introducción}

A continuación se presenta el estudio de la primera etapa de la edición de textos con criterio filológico en la obra El maestro de escuela (1941), con el propósito de dar a conocer todas las vicisitudes que ha tenido la obra desde su momento fundacional en 1941 hasta nuestros días. En este estudio será fundamental ofrecer al lector la información relacionada con el material pretextual, textual y paratextual, con el número de ediciones y reimpresiones, sus lugares de publicación, así como de los sitios de consulta, difusión y recepción. De igual forma se indagará por la historia de transmisión textual que ha tenido la obra en sus ochenta años exactos de historia editorial. Finalmente, se presentará un ejemplo de la caracterización de las ediciones y se establecerá el texto base de la fijación, componente central de esta y requisito fundamental de cualquier tentativa de realizar un trabajo de edición con criterios académicos.

\section{Marco teórico}

El propósito de la crítica textual es entregar un texto académico para que críticos y lectores contemporáneos puedan realizar nuevas valoraciones estéticas de la obra editada con criterio filológico, es decir, la crítica textual o ecdótica es la teoría base para la ejecución de una edición crítica y es la encargada, desde la época de la Biblioteca de Alejandría, de garantizar la transmisión de los textos en el tiempo. Ahora bien, nuestra tradición crítico-textual parte del principio filológico que opera en las ediciones críticas de textos manuscritos de la tradición hispánica peninsular, es decir, de la recuperación del texto original tal como fue escrito por su autor y transmitido por copistas, antes de la llegada de la imprenta, en un momento determinado del desarrollo histórico en la península ibérica. Sin embargo, la forma de analizar ambas tradiciones obedece a los mismos principios teóricos y metodológicos generales con toda la exhaustividad científica propia de la ciencia contemporánea y, en nuestro caso en particular, la adaptación de estos principios aplicados en España a nuestros textos transmitidos de forma impresa y no trasmitidos en fuentes manuscritas. 
Así, la crítica textual o ecdótica se constituye como una disciplina teórico-metodológica que tiene el objetivo de fijar unos principios teóricos y utilizar unas pautas metodológicas que se ajustan dependiendo de las condiciones del objeto de estudio, pero con los procedimientos que implican todo el trabajo filológico, es decir, la adaptación del método científico a la investigación literaria, porque "la gran novedad en la filología del siglo xx [...] es la fundación científica de la recensio" (Blecua, 2012, p. 31); y es que justamente el método científico es la arquitectura que facilita la recolección, sistematización y el análisis del material base: las lecciones y las variantes. Estos principios teóricos son tres y en ellos se encuentra la fuente teórica y la ejecución metodológica para la elaboración de ediciones críticas o con criterio filológico, a saber: Recensio, Constitutio textus y Dispositio textus.

La primera fase, recensio, sobre la que se centra el presente estudio, es el "análisis de las variantes de todos los testimonios y la filiación de estos [...] de tipo exhaustivo" (Blecua, 2012, p. 31); consiste en el levantamiento y sistematización de todos los testimonios - relacionados con los objetos de estudio- encontrados de la obra en las diferentes bases de datos, catálogos digitales y bibliotecas nacionales e internacionales, con el fin de establecer todas las filiaciones entre una y otra edición o testimonio para aproximarse al arquetipo y así reconocer los testimonios por medio de la descripción de las ediciones y su materialidad (medios, condiciones físicas, divulgación o circulación), bajo la cual, en este caso particular, la novela de Fernando González fue publicada en diferentes momentos de su historia de transmisión textual. El paso final de la recensio es la selección del texto base que en mucha ocasiones corresponde —en nuestra tradición impresa - con la edición príncipe o primera edición. Una vez hallados todos los testimonios, se procede a la selección de las ediciones más significativas y divergentes en la historia de transmisión, es decir, aquellas que presentan cambios que afectan la gran mayoría de los diferentes niveles de lengua (ortográfico, semántico, pragmático, morfológico, entre otros), también conocidos como lecciones que, agrupadas en conjuntos, se denominan variantes.

El segundo procedimiento o constitutio textus es la colación de los testimonios seleccionados con el texto base, que nos permite visualizar gráficamente la historia de transmisión textual y, así, identificar las relaciones textuales entre cada una de las ediciones o testimonios comparados. Una vez cotejados todos los testimonios con el 
texto base, son examinadas y seleccionadas sus variaciones para construir la tipificación de dichos cambios y frecuencias, con el fin de determinar los lugares precisos donde se debe intervenir editorialmente la novela. La selección de los cambios obtenidos como resultado del análisis de la colación o collatio "supone un reconocimiento de la prevalencia de unas variantes sobre otras y, en realidad, se sugiere una enmienda de las que resultan menos válidas" (Pérez Priego, 2011, p. 69); lo anterior implica la necesidad de contemplar la historia de transmisión del texto, sus medios de producción, el contexto espacio-temporal y, sobre todo, el comportamiento de la gramática y la ortografía desarrollada en la vida editorial de la obra, lo que significa poco más de un siglo de historia ortográfica y gramatical de la lengua española.

Una vez obtenidas las conclusiones de este proceso, se puede culminar el último momento de la constitutio textus o, en otras palabras, la "fase decisoria, más pragmática, que tiene como fin dar un texto crítico concreto a los lectores” (Blecua, 2012, p. 33), que consiste en la valoración filológica de las variantes que estén menos relacionadas con el texto base definido por el crítico textual; esto con el propósito de analizar la historia de transmisión del texto y entender qué ocurrió, por ejemplo en la novela $E l$ maestro de escuela, con las arbitrariedades en la forma de los registros de las voces de los personajes.

La última operación, o dispositio textus, es el momento en el que el editor crítico enfrenta la decisión sobre la apariencia formal de la obra: "reconstruido teóricamente el texto del arquetipo más próximo al original, seleccionadas las variantes [...] y enmendados los errores, el editor se ve todavía ante la tarea de presentar y ofrecer aquel texto de la manera más clara e inteligible posible” (Pérez Priego, 2011, p. 79). Esto es, la construcción del aparato crítico que consiste en dos expresiones: la primera, las variantes a pie de página que explican las intervenciones del editor crítico o la razón por la que no se decide intervenir la obra. En suma, corresponde a los criterios usados por el editor crítico para fijar la obra, respetando el usus scribendi o las fórmulas gramaticales y ortográficas propias del autor. La segunda expresión del aparato crítico son las notas explicativas al final del texto fijado, que amplían y contextualizan el universo referencial de la obra. Estas tres fases de la crítica textual aplicadas en la edición crítica garantizan un producto riguroso y académico que permite una nueva lectura, comprensión e interpretación de las obras editadas con criterio filológico. 


\section{Resultados y discusión}

El presente apartado presenta el estudio y análisis de la recensio en la novela El maestro de escuela (1941) del escritor colombiano Fernando González. Este estudio, como se expresó antes, tiene su cometido desde la perspectiva teórico-metodológica de la crítica textual, específicamente desde la etapa de la recensio, con el propósito de restablecer la novela en edición crítica en una versión lo más fidedigna con respecto a la intención primigenia del escritor en el momento de su creación. De este modo, se dará a conocer una exposición de los momentos de la recensio en el contexto de El maestro de escuela, con su respectiva interpretación filológica, con el propósito de determinar las modificaciones, alteraciones y filiaciones que ha sufrido el texto en el proceso de transmisión textual o historia editorial.

En esta fase de la recensio se procura mostrar la visibilidad, las restricciones, las posibilidades y el desarrollo de la novela El maestro de escuela en bases de datos, catálogos, sitios web y otras fuentes donde se dé información de la divulgación bibliográfica en los contextos nacional e internacional. A este respecto, se tiene que la obra cuenta con ochenta años de transmisión textual sintetizados en siete ediciones (de las cuales, a pesar de tener la denominación de "edición", se tiene la seguridad de que dos de ellas son reimpresiones, como se verá más adelante), difundidas todas en formato impreso y una versión digital de la Corporación Otraparte, que se basa en la séptima edición de la misma (la que corresponde al Fondo Editorial Universidad Eafit, como se verá luego), con última fecha de revisión del 18 de febrero de 2020.

\section{Historia de transmisión de los testimonios}

La presente historia de difusión y transmisión de El maestro de escuela presenta los testimonios textuales (ediciones, reediciones y reimpresiones), y apartará para otro momento el análisis y la recopilación de los materiales paratextual y postextual (la recepción de la novela, así como sus adaptaciones, traducciones y reelaboraciones). Cabe destacar que se cuenta con un mecanuscrito que reposa en el Archivo Fernando González de la Corporación Otraparte, documento que servirá para su respectivo inventario, clasificación y estudio, pues como testimonio pretextual directo de la obra aportará información sustancial y de primera mano para lograr un procedimiento y tratamiento más seguro en el proceso de restauración de El maestro de escuela desde su origen en 1941. 
Si tenemos en cuenta lo anterior, podemos decir entonces que la búsqueda de la historia de la transmisión de la obra se puede agrupar en fuentes de información bibliográficas confiables y con relevancia nacional; se pueden citar acá las bases de datos y los catálogos de las bibliotecas universitarias como los de la Universidad Nacional de Colombia, la Colección Patrimonio Documental de la Universidad de Antioquia, en donde se concentran grandes obras y diferentes estudios patrimoniales de la cultura y el arte colombiano, la Universidad Tecnológica de Pereira y la Biblioteca Luis Echavarría Villegas de la Universidad Eafit (con la primera y cuarta ediciones de la novela en la Colección Patrimonial “FAes”). También la búsqueda contempló otras importantes bases de datos bibliográficos como la Biblioteca Pública Piloto, la Biblioteca Luis Ángel Arango, la Biblioteca José Manuel Rivas Saconni del Instituto Caro y Cuervo y la Biblioteca Municipal de Manizales, pues estas importantes bibliotecas presentan informaciones muy completas relacionadas con el hallazgo de los testimonios de la obra de Fernando González.

El examen de indagación en los diferentes servidores permite evidenciar que la totalidad de la producción de Fernando González se encuentra en la mayoría de estas fuentes de información, ya que abarcan y engloban los diferentes materiales, en su mayoría impresos, en los que ha circulado la creación de este autor, desde Pensamiento de un viejo en 1916 hasta Las cartas de Ripol en 1964, año de su muerte. En esta perspectiva, se puede aseverar entonces que la obra El maestro de escuela está referenciada en todas estas fuentes de información y documentación, tanto en su primera edición de la Editorial ABC en 1941, como en sus siguientes ediciones en formato de libro, que van desde el año ya mencionado hasta el año 2012, para un total de cinco ediciones y dos reimpresiones.

Esta búsqueda de la historia de transmisión de El maestro de escuela también se ve enriquecida con los aportes que se encontraron en fuentes de información bibliográficas alternativas, como las encontradas en la web, siendo la más relevante y considerable la que hace la página de la Corporación Otraparte, donde se puede encontrar toda la información especializada respecto al autor y su obra y, de manera especial, la novela objeto de estudio del presente texto en formato digital, la cual está en constante revisión y actualización. Así mismo, existen páginas web institucionales como la del Banco de la República y un blog cubano de relevancia considerable que contiene información del autor y su obra. De igual manera, es de anotar que las ini- 
ciativas en la red acerca de la difusión, comentarios, reseñas y escritos sobre esta obra, que se concentran en iniciativas de fuentes no oficiales, es decir, las que emprenden lectores o admiradores del autor y su producción literaria y académica, son numerosas. Se deben mencionar, por ejemplo, los siguientes enlaces en donde se registra en formato digital o fragmentos de esta con fines culturales:

Tabla 1. Testimonios de la obra en fuentes web ${ }^{\mathrm{I}}$

\begin{tabular}{|c|c|}
\hline Fuente & URL \\
\hline Corporación Otraparte & $\begin{array}{c}\text { https://www.otraparte.org/fernando-gonzalez/obra/ } \\
\text { ediciones/el-maestro-de-escuela/ }\end{array}$ \\
\hline Banco de la República & $\begin{array}{c}\text { https://enciclopedia.banrepcultural.org/index.php/ } \\
\text { Fernando_Gonz\%C } 3 \% \text { Arlez_Ochoa }\end{array}$ \\
\hline $\begin{array}{l}\text { Enciclopedia colaborativa } \\
\text { en red EcuRed }\end{array}$ & $\frac{\underline{\text { https: } / / \text { www.ecured.cu/Fernando_Gonz } \% C_{3} \% \text { AIlez_}_{-}}}{\text {Ochoa }}$ \\
\hline
\end{tabular}

En los enlaces de la tabla 1, así como otros que no se registran, que como ya se dijo hacen parte de entidades o instituciones de seriedad académica respaldada y garantizada, se encuentran todo tipo de informaciones relacionadas con la obra de este autor, su trayectoria y vida, siendo el más relevante el link: www.otraparte.org, página dedicada al autor y donde está el repositorio completo de sus escritos, incluyendo la obra objeto de estudio del presente texto.

Un balance de esta historia de transmisión evidencia que El maestro de escuela se halla en todas las fuentes de información y documentación antes relacionadas, incluyendo la obra completa en la fuente digital aludida en el párrafo anterior. Por otro lado, la búsqueda en bases de datos a nivel internacional también presenta significativos aportes para evidenciar la recepción de esta en otras latitudes. La obra se encuentra en repositorios como los de las bibliotecas de la Universidad de Chile, la Universidad de Cambridge, la Universidad de Oxford, la Universidad Simon Fraser en Canadá, la Universidad de Buenos Aires, la Universidad de Pamplona y en más de diez universidades de Estados Unidos como las de Harvard y Yale; así mismo, se encuentra en bibliotecas como las del Instituto Iberoamericano de Berlín y la biblioteca del Congreso de Estados Unidos; esto da muestra de los alcances de la obra por fuera del territorio nacional, llegando a otros tipos de lectores con otras lenguas distintas al español y con diferentes creencias e ideologías.

$1 \quad$ Todas las tablas aquí presentadas son de elaboración propia. 
Por último, se debe resaltar que emprender el cometido de este trabajo filológico sobre el estudio la obra El maestro de escuela es de mucha importancia en los estudios literarios contemporáneos, dado que esto garantiza la restauración completa y lo más exacta posible de la historia de la transmisión, en este caso editorial, para la consolidación de una investigación y análisis metódico y sistemático de los testimonios de la obra para, finalmente, establecer su fijación textual en edición crítica.

Finalmente, se puede decir que, con base en la búsqueda de los diferentes testimonios y su relacionamiento con las bases de datos, catálogos y demás fuentes de información donde se pueden encontrar, contamos con un material suficiente y considerable, tanto pretextual como textual, y las formas de ubicarlo, para la realización de la edición crítica de El maestro de escuela, que tiene como fin básicamente el de restituir este texto suprimiendo los deterioros y adherencias mal constituidas que sufrió con el paso de los años, dado que la escritura, como bien plantea Blecua en el epígrafe de este artículo, se reviste complejidad debido a los procesos psicológicos y mecánicos inherentes en dicho acto. Todo esto con el propósito de lograr en la medida de lo posible la primigenia intención estética que salió de las manos de su autor; esto, como ya se demostró, con un conocimiento profundo de la historia de su transmisión.

\section{Relación de los testimonios}

Una vez dada cuenta de la historia de la transmisión de los testimonios de la novela de Fernando González, a continuación en las tablas 2, 3 y 4 se presentan los datos generales de la obra y los cuadros síntesis que contienen la relación pretextual y textual de todos los testimonios de El maestro de escuela en sus ochenta años de historia editorial:

Tabla 2. Datos generales de identificación de la novela

\begin{tabular}{|c|c|}
\hline Título de la obra & El maestro de escuela \\
\hline Autor & Fernando González Ochoa \\
\hline Año de publicación & I94I \\
\hline Género literario & Novela \\
\hline $\begin{array}{l}\text { Contenidos (número de capítulos, } \\
\text { apartados, división de la obra) }\end{array}$ & $\begin{array}{c}\text { Prólogo, } 29 \text { capítulos numerados en arábigos, un apartado titulado } \\
\text { "Algunos de los apuntes de Manjarrés" (con I8 subdivisiones no } \\
\text { numeradas y con el siguiente formato: }[\bullet \bullet \bullet]) \text {, un epilogo y un } \\
\text { aparte titulado "El idiota" }\end{array}$ \\
\hline $\begin{array}{l}\text { Características especiales } \\
\text { (Ilustraciones, mapas, otros) }\end{array}$ & Dedicatoria a Thorton Wilder \\
\hline
\end{tabular}




\begin{tabular}{|c|c|c|c|c|c|c|c|c|c|}
\hline | & $\frac{\pi}{z}$ & $\frac{\pi}{z}$ & 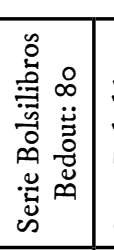 & 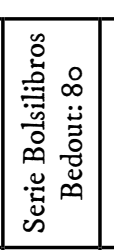 & $\frac{\pi}{z}$ & $\frac{\pi}{z}$ & $\frac{\pi}{z}$ & 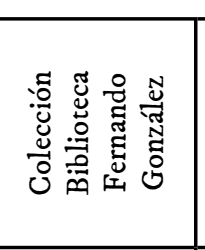 & $\widehat{\widetilde{z}}$ \\
\hline | & $\begin{array}{l}7 \\
9\end{array}$ & 勇 & $\underset{9}{7}$ & 年 & 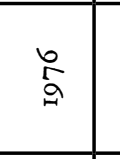 & 参 & & & $\star \star$ \\
\hline 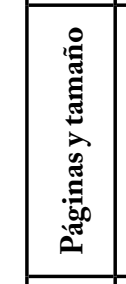 & 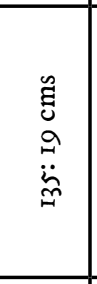 & 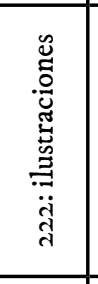 & 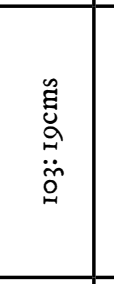 & 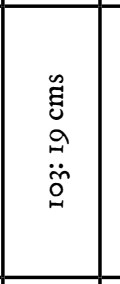 & $\cong$ & 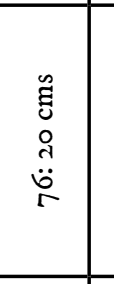 & 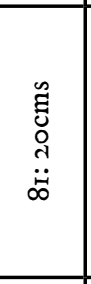 & 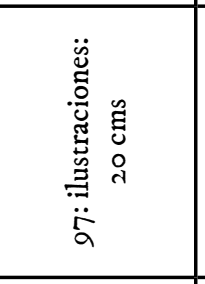 & $\therefore$ \\
\hline $\mid$ & 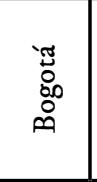 & 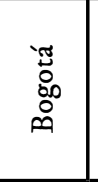 & 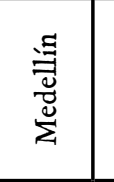 & 丞 & 鸹 & 苞 & $\begin{array}{l}\text { 总 } \\
\text { 惫 }\end{array}$ & 急 & $\begin{array}{l}\text { 总 } \\
\text { 离 } \\
\text { 离 }\end{array}$ \\
\hline 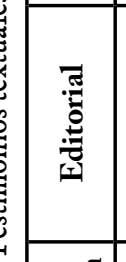 & 曾 & 曾 & 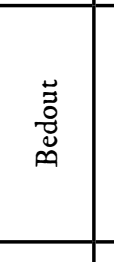 & 言 & 㲋 & 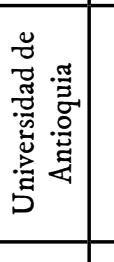 & 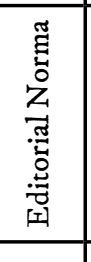 & 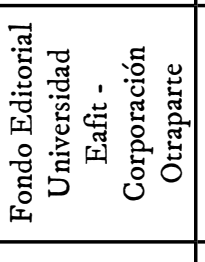 & 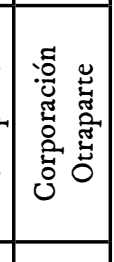 \\
\hline \begin{tabular}{|l|l|} 
\\
\\
\end{tabular} & $\underset{7}{7}$ & $\begin{array}{l}7 \\
2\end{array}$ & $\stackrel{\circ}{\vdots}$ & 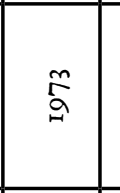 & 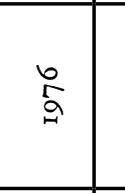 & hà & $\begin{array}{l}\infty \\
\mathrm{a}\end{array}$ & 吾 & $\begin{array}{l}\infty \\
\text { of } \\
\text { d. }\end{array}$ \\
\hline 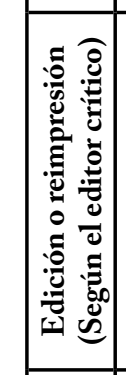 & 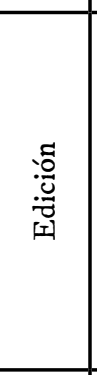 & 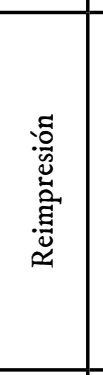 & 溥 & 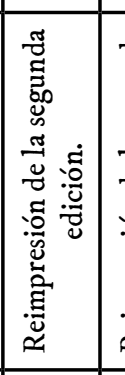 & 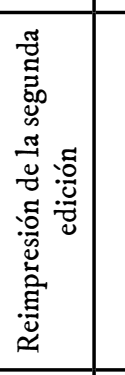 & 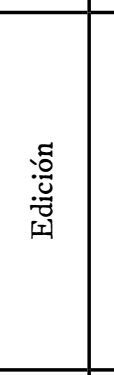 & 湔 & $\begin{array}{l}\text { 滂 } \\
\text { 离 }\end{array}$ & 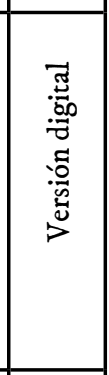 \\
\hline 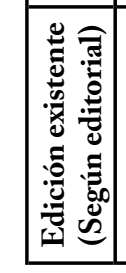 & 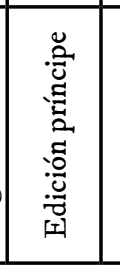 & 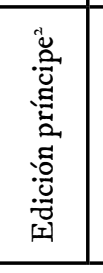 & 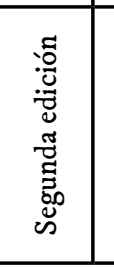 & 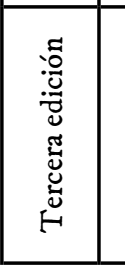 & 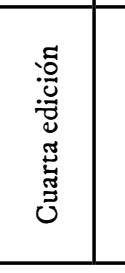 & 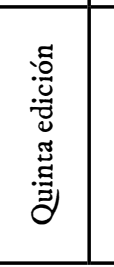 & 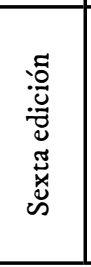 & 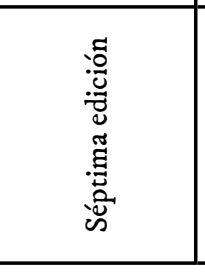 & $\frac{\pi}{z}$ \\
\hline
\end{tabular}


Tabla 4. Testimonio pretextual de la novela

\begin{tabular}{|c|c|c|c|c|c|c|}
\hline Obra & $\begin{array}{c}\text { Fecha de } \\
\text { publicación }\end{array}$ & Formato & Dimensiones & Hojas & $\begin{array}{c}\text { Fuente de } \\
\text { información }\end{array}$ & $\begin{array}{l}\text { Descripción } \\
\text { general }\end{array}$ \\
\hline $\begin{array}{c}\text { El maestro } \\
\text { de escuela }\end{array}$ & I2/O2/I94I & Mecanuscrito & $\begin{array}{l}27,5 \mathrm{~cm} \text { alto } \mathrm{x} \\
21,8 \mathrm{~cm} \text { ancho }\end{array}$ & $7 \mathrm{I}$ & $\begin{array}{l}\text { Archivo } \\
\text { Fernando } \\
\text { González, } \\
\text { Corporación } \\
\text { Otraparte }\end{array}$ & $\begin{array}{c}\text { Inscripción } \\
\text { de la fecha al } \\
\text { final de la obra. } \\
\text { Obra completa } \\
\text { mecano- } \\
\text { escrita. Cuenta } \\
\text { con algunos } \\
\text { recortes } \\
\text { propios de la } \\
\text { construcción } \\
\text { creativa de } \\
\text { la misma y } \\
\text { fragmentos } \\
\text { individuales } \\
\text { en hojas } \\
\text { separadas. }\end{array}$ \\
\hline
\end{tabular}

La tabla 2 funge como una síntesis del contenido textual de la novela, mientras que las tablas 3 y 4 dan cuenta de la relación de los testimonios pretextuales y textuales de la obra en su historia de transmisión. En las tres se condensa la información más completa no solo de la historia editorial de cada edición, sino también de los elementos constitutivos de cada testimonio.

Teniendo en cuenta la presente relación de testimonios se puede concluir que El maestro de escuela ha tenido una historia de transmisión relativamente breve que va desde 1941 hasta 2020, que se traduce en un mecanuscrito impreso, en cinco ediciones, dos reimpresiones y una versión digital; de igual manera, que dicha obra ha sido editada casi en su totalidad en la ciudad de Medellín, exceptuando la primera y la sexta ediciones que se publicaron en Bogotá. En este mismo sentido, se debe decir que las editoriales que la han editado son todas de reconocidos renombres y reputación en el campo académico, como en los casos de las universidades Eafit y de Antioquia, así como la extinta Editorial Norma.

Como se pudo observar en la tabla 3, la Editorial ABC de Bogotá es la encargada de publicar en 1941 por primera vez El maestro de escuela de Fernando González. Esta editorial, según cuenta Miguel Ángel Pineda Cupa (2019), en 1936 estaba sobre la Avenida Jiménez de Quesada \# 22, y era presidida por Carlos A.Jiménez. La misma, en su momento, publicó dos obras del autor, la ya mencionada y Santander, en 1940 (p.71). 
Tendrán que pasar casi treinta años para que El maestro de escuela vuelva a llamar la atención por parte de la industria editorial colombiana. Es así como en la década de los setenta la Editorial Bedout, posterior a la muerte del escritor, hizo un trabajo de tres ediciones en 1970, 1973 y 1976, con lo que se da a conocer masivamente la novela en diferentes contextos nacionales, dada la particularidad de la Editorial Bedout de difundir de manera contundente y mediante ediciones de bolsilibros escritores representativos de la tradición literaria nacional e internacional. Quizá este sea uno de los proyectos más ambiciosos de la industria cultural que se tuvo en el siglo xx en Colombia, toda vez que la editorial fundada por Félix de Bedout Moreno en 1889, ${ }^{3}$ con el nombre de Tipografía Bedout (Tipografía del Comercio), aspiraba a llegar a todos los hogares colombianos mediante sus colecciones populares a muy bajo costo. En el momento en que surgían todas las grandes empresas antioqueñas, Bedout llegó a ser uno de los pilares de la industria editorial en Antioquia y de las artes gráficas en Colombia. De acuerdo con Margarita Valencia (s.f.), del Instituto Caro y Cuervo, el despegue de la industria gráfica y editorial en Colombia se dio alrededor de tres empresas, siendo Bedout, en Medellín, una de ellas (párr. 2). Esta tipografía fue relevante en su época para la impresión de textos escolares y billetes para el Banco de la República.

Editorial Bedout fue determinante en la difusión, publicación y reimpresión de varias obras de Fernando González, entre ellas: Pensamientos de un viejo (1970, Volumen 81), Viaje a pie (1969 aprox., Volumen 90), Mi Simón Bolivar (1969, Volumen 55), Don Mirócletes (1973, Volumen 141), El hermafrodita dormido (1971, Volumen 94), Mi compadre (1970 aprox., Volumen 71), El remordimiento. (Problemas de teología moral) (1972, Volumen 115), Cartas a Estanislao (1972, Volumen 117), Los negroides (Ensayo sobre La Gran Colombia) (1970, Volumen 67), Santander (1971, Volumen 89), Libro de los viajes o de las presencias (1973, Volumen 142), entre otras.

Luego de la vitalidad de la publicación, difusión y recepción que tuvo la novela en la década de los años setenta del siglo xx, vino otro gran periodo de silencio editorial de casi veinte años, hasta que las editoriales Universidad de Antioquia y Norma la publican de nuevo en 1995 y en 1998, respectivamente. La primera, fundada en 1929, se caracteriza por realizar publicaciones de gran talla académica de obras literarias uniuna importante cantidad de empleos en Medellín. 
versales de todos los tiempos, tal como reza en su página oficial, y tiene como objetivo “seleccionar obras con los mejores estándares de calidad académica, creativa y de escritura, originadas en la Universidad de Antioquia o fuera de ella, para configurar un catálogo de títulos de las diversas áreas del saber y de la creación" (Editorial Universidad de Antioquia, s.f.). Esta editorial ha publicado títulos del autor tales como Antioquia, novela hecha por entregas (1939), Viaje a pie (1993, 1995), Correspondencia (1995), El remordimiento (Problemas de teologia moral) (1994) y Nociones de izquierdismo (2000).

En cuanto a la Editorial Norma (1960-2011), se puede decir que, Según Natalia Ardila Garzón (2017), fue quizá una de las empresas editoriales colombianas más recordadas y reconocidas durante el siglo xx. Nace oficialmente el 23 de abril de 1960 en Colombia y, desde sus principios, se enfoca en la producción de libros de texto y de interés general; esta editorial en 1990 alcanzó a imprimir 2000 títulos y llegó a cubrir el 70\% de la producción nacional, llegando a veintiséis ciudades del territorio nacional. En este punto de relevancia, Editorial Norma alcanzó a producir veintiséis colecciones diferentes, entre las que podemos encontrar: Cara y Cruz, Milenio, La Máquina delTiempo, La Otra Orilla y la publicación de variadas novelas, entre otros, así como de ediciones muy atractivas que abarcan todas las temáticas de interés para el público en general.

De la relación de las publicaciones de Fernando González con esta editorial se puede decir que solo publicó el título El maestro de escuela, objeto de estudio del presente escrito, en una edición de 1998 en la Colección Milenio, la cual se caracteriza "por publicar a autores canónicos como Miguel de Cervantes, Apollinaire, Quevedo, Henry James, con ediciones de ejemplares de bajo costo con venta segura, dada la importancia de los autores y de sus obras" (Ardila Garzón, 2017, p. 2). Un proyecto editorial de resonancia internacional que, desafortunadamente, a la fecha no existe, pero que dejó una huella importante en el contexto cultural del país.

Catorce años después de la edición de Norma, El Fondo Editorial Universidad Eafit en conjunto con la Corporación Otraparte realizan la publicación impresa más reciente de El maestro de escuela en 2012. Otra institución universitaria interesada en el legado literario de Fernando González, lo cual es normal si tenemos en cuenta que este Fondo Editorial se caracteriza por "acoger y desarrollar todos aquellos proyectos editoriales que tengan como misión apoyar y fortalecer la producción intelectual, científica y literaria que se genera en la Universidad, y contribuye a la divulgación y 
circulación de obras significativas para el desenvolvimiento social y cultural de nuestra comunidad" (Fondo Editorial Universidad Eafit, s.f.a). Esta edición, sacada en conjunto por las dos entidades reconocibles en este apartado, hace parte de una iniciativa llamada Biblioteca Fernando González, sobre la que se dice, en la página oficial de la Universidad Eafit lo siguiente:

La Editorial EAFIT y la Corporación Otraparte se asocian para publicar esta colección, compuesta por los diferentes títulos que integran la obra de Fernando González Ochoa. El diseño de la serie está inspirado de alguna forma en las libretas que el autor empleó para registrar sus pensamientos, sus escritos. El objetivo es que la obra de este importante autor antioqueño alcance mayor divulgación mediante la reimpresión, inicialmente, de los títulos más leídos agotados en la actualidad, hasta llegar a la publicación de la biblioteca completa (Fondo Editorial Universidad Eafit, s.f.b).

Esta colección ha publicado títulos como: Cartas a Simón (2017), El hermafrodita dormido (2016), Libro de los viajes o de las presencias (2018), Los negroides - Ensayo sobre la Gran Colombia (2014), Nociones de Izquierdismo (2015), Pensamientos de un viejo (2007, 2016), Salomé - El remordimiento (2008), Una tesis. El derecho a no obedecer (2019), Viaje a pie (2010) y la obra objeto de estudio de este escrito, El maestro de escuela, publicado en 2012. Como se puede observar, es este proyecto editorial el que ha actualizado gran parte de la obra de González en lo que va corrido de este siglo.

Finalmente, en 2020 se cuenta con la publicación web de la novela por parte de la Corporación Otraparte, basada en esta última edición de 2012. Sea este el momento para resaltar el papel de la mencionada Corporación como salvaguarda del patrimonio literario y cultural de Fernando González:

Creada el to de abril de 2002 por iniciativa de Simón González Restrepo, hijo menor del pensador, y cuyos objetivos principales son difundir y preservar el legado del escritor Fernando González Ochoa, convertir la Casa Museo Otraparte en un centro cultural con proyección internacional y preservar el área como parque y jardín para beneficio de la comunidad y la protección del medio ambiente. De esta manera, el proyecto Parque Cultural Otraparte surge como un clamor para que Colombia se reencuentre con el mensaje y la filosofía de Fernando González, tan inédito todavía, tan desconocido todavía, pero siempre tan inquietante y provocador, porque en Otraparte late y habita, y no se apaga ni extingue, el corazón del caminante envigadeño(Corporación Otraparte, 2002).

En síntesis, se puede demostrar que los cuatro periodos en los cuales se ha concentrado la historia de transmisión de El maestro de escuela son disímiles y se pueden clasificar de la siguiente forma. El primero corresponde a la edición príncipe de ABC en 1941, en vida del escritor, cuando está finalizando una etapa de esplendor en su producción creativa que inició en 1916 y se consolida en la década de los años treinta, años de los 
que datan la mayoría de sus producciones literarias. El segundo periodo corresponde a un silencio prolongado, luego de la muerte del escritor, para que la novela vuelva a editarse. Tres décadas tendrán que pasar para que El maestro de escuela tenga una segunda edición, esta vez en Bedout en 1970, tiempo muy amplio que da cuenta de la poca difusión y recepción que tuvo la obra en vida del escritor por parte de la prensa, los críticos y la misma academia nacional. Podrían aventurarse muchas hipótesis del porqué de esta situación, lo cual solo se corroboraría a partir de un riguroso estudio de recepción; baste decir, por ahora, que El maestro de escuela no tuvo la gran acogida de otras obras en vida del escritor, lo que significó un silencio editorial y de la misma crítica literaria, al tiempo que un proceso de limitada difusión y reconocimiento nacional e internacional de la obra en mención. El tercer periodo, casi veinte años después de la última reimpresión de Bedout (1976), coincide con el centenario del natalicio del escritor, pues en 1995 la Universidad de Antioquia publica de nuevo su novela; tres años más tarde hace lo propio la Editorial Norma. Durante esta década varias editoriales se dedican a difundir y publicar las principales obras de Fernando González. No es gratuito que tengan que pasar casi dos décadas para que su obra vuelva a figurar en el panorama literario nacional, pues al parecer el legado de Bedout alcanzó a irradiar este periodo en colegios, bibliotecas y centros culturales, dada la masiva publicación de sus ediciones y a su formato de bolsilibro que ayudaba de manera económica y práctica a su masiva adquisición. Será entonces gracias a una nueva efeméride del escritor que se rescata nuevamente su figura y obra en el escenario editorial del país. El último periodo, catorce años después, corresponde a la última publicación de El maestro de escuela por parte del Fondo Editorial Universidad Eafit (2012) en asocio con la Corporación Otraparte. Este periodo se caracteriza por el fuerte interés institucional de la mencionada Corporación por la organización y sistematización del archivo personal del escritor, así como de todos los documentos y materiales relacionados con su obra. Desde ese momento hasta entonces dicho propósito se mantiene con igual empeño y con la responsabilidad y el compromiso que implica el estudio y la conservación de los materiales pretextuales y textuales del artista envigadeño.

En conclusión, podemos decir que entre periodo y periodo transcurren muchos años en la publicación de la novela: 29, 19 y 14 años, respectivamente, lo que evidencia un bajo perfil en la historia de publicación de El maestro de escuela, el cual queremos subsanar con una nueva edición, esta vez en edición crítica o académica, que 
permita nuevas y renovadoras lecturas de la novela, así como nuevos acercamientos críticos que den cuenta de la recepción de la obra, de su valor estético e importancia dentro de la tradición literaria nacional. Es justo este el propósito de la investigación en la que se enmarca el presente texto, una edición crítica de la obra completa de Fernando González que permita una mirada distinta de su producción literaria y con ello nuevos lectores y estudiosos de su legado literario y cultural.

\section{Caracterización de los testimonios}

Después del recuento de la búsqueda de los testimonios de la obra El maestro de escuela del escritor colombiano Fernando González y la respectiva relación y valoración de estos, pasamos a sus caracterizaciones. En este apartado por asuntos de espacio solo se presenta la descripción y el análisis del primer testimonio de la obra, es decir las características más importantes de dicho testimonio a lo largo de su historia de transmisión en el contexto editorial colombiano. Se dejará para otro momento la caracterización completa del resto de los testimonios pretextuales y textuales.

Antes iniciar con dicha caracterización, es importante mencionar que para 1941, año en que se publica por primera vez El maestro de escuela, existía en la ciudad de Medellín la librería La Pluma de Oro, ubicada en la calle Carabobo, a cargo de Guillermo Johnson E. Sobre esta, el mismo González escribiría una carta dedicada a su dueño lo siguiente:

\footnotetext{
Permítame felicitarlo por su librería y editorial La pluma de oro.

Usted le ha dado novedad a esto de librerías en Medellín. Usted, y el doctor Marco Aurelio Arango con su editorial Atlántida, están remozando el espíritu antioqueño. Hacía falta ese lugar en la carrera Carabobo, en ese rincón o remanso de la calle populosa, la más antioqueña de Medellín. Precisamente allí donde es mayor el tráfico, yendo de sur a norte, a poco de pasar el Palacio de Justicia, sale repentinamente una casa y se mete en la calle, angostándola y dejando un rincón, formando un ángulo recto: pues allí, en ese remanso, era el lugar propio para vender el libro moderno, las ediciones baratas y elegantes de "las obras maestras" (González, 2007, p. 2).
}

Como se puede observar, este espacio literario fue representativo de la cultura literaria de la ciudad, al tiempo que instancia para el intercambio y la venta de libros de todo tipo, entre ellos las obras del escritor envigadeño.

En conversación con Gustavo Restrepo, director ejecutivo de la Corporación Otraparte, manifiesta que el afiche de la figura 1 corresponde a un regalo que hizo el investigador Miguel Escobar Calle hace muchos años a la Corporación. Además, 
afirma que "Escobar Calle fue el coordinador de la Sala Antioquia de la Biblioteca Pública Piloto durante un largo periodo, fue gran amigo de Fernando hijo y murió siendo miembro de nuestra junta directiva". Dicho afiche fue publicado en 2008 en el sitio Web de la Corporación: https://www.otraparte.org/boletin/20081007-bol-70.html

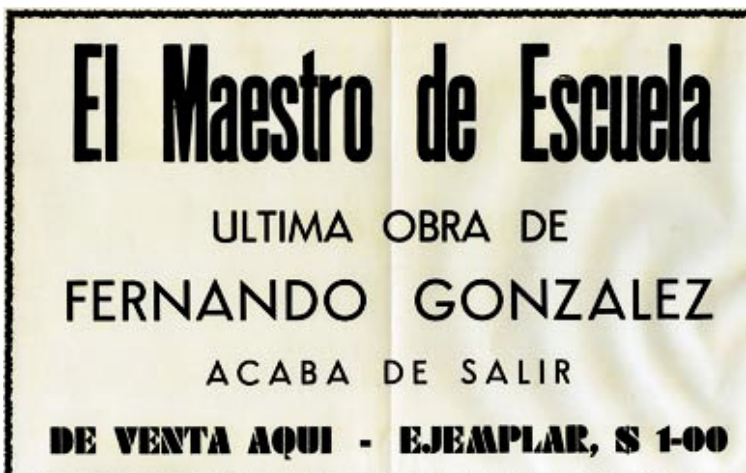

Figura 1: Afiche ubicado en 1941 en la Librería La Pluma de Oro

\section{El maestro de escuela (1941) Editorial ABC}

La obra El maestro de escuela fue publicada en su primera edición por la Editorial $\mathrm{ABC}$ en la ciudad de Bogotá. Su portada es sencilla, en cartón manila, en la que aparece en la parte superior derecha el nombre del autor en un color verde en mayúscula sostenida; lo mismo ocurre con el título de la obra, ahora en rojo y con una fuente de mayor tamaño en el centro de la carátula. Líneas más abajo se sitúa en el centro el año de publicación (1941) con color verde y, por último, en la sección inferior centrada, el logotipo de la Editorial $\mathrm{ABC}$ (véase la figura 2).

El tamaño de la edición es de 19 x $11 \mathrm{~cm}$, no posee ilustraciones o imágenes distintivas, cuenta con una dedicatoria a Míster Thornton Wilder que reza así: "Homenaje a Thornton Wilder, el creador del drama eterno. 'Our Town”' (González, 1941, p. 9), escritor del que el mismo autor diría luego que es un "dramaturgo yanqui, vino a visitarme. Dizque admira mucho mi obra; díjome que este año llamaría la gloria a mi puerta (González, 2011, párr. 11); dedicatoria que en este caso funciona más como un reconocimiento al escritor estadounidense que como un pretexto narrativo de amplios vínculos dialógicos con el contenido textual de la novela. 
Como se expresó antes, por asuntos de espacio no se continúa con la presente caracterización ni con los otros seis testimonios de la novela. Baste decir que la caracterización sirve para un mejor conocimiento y comprensión de la materialidad de las ediciones, de sus rasgos distintivos, así como de sus formas estilísticas y apuestas estéticas en su corporeidad. Para el caso de este primer testimonio es fundamental comprender que no hubo una apuesta estética por parte de la editorial bogotana, ni mucho menos un cuidado especial de esta edición príncipe; por el contrario, se observa una edición comercial muy básica, sin ilustraciones ni fotografías, y con un marcado acento en una producción de consumo popular. En síntesis, este primer testimonio evidencia la falta de una apuesta editorial por el autor, y un interés comercial en una producción literaria de la que no se espera mayores repercusiones de recepción.

Fuente: Corporación Otraparte

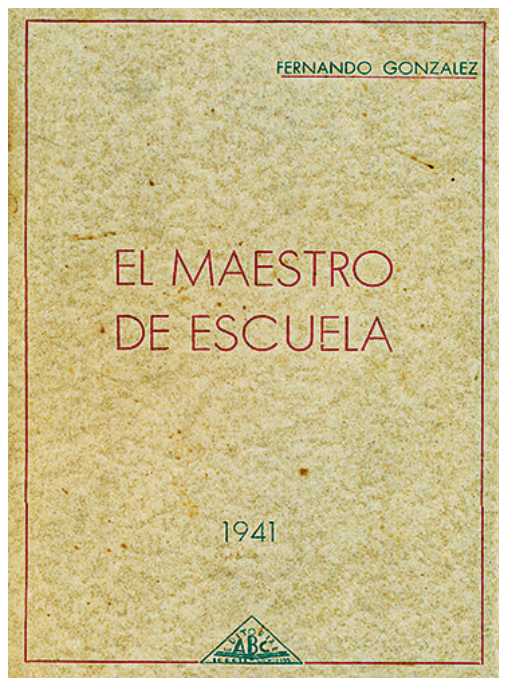

Figura 2: Portada de El maestro de escuela, Editorial ABC (1941)

\section{Establecimiento del texto base}

El propósito de este apartado es establecer el texto base, o texto de la colación según Pérez Priego (2011, p. 127), de la novela de González, con el firme propósito de iniciar la siguiente etapa de la crítica textual o de edición de textos con criterios filológicos, la constitutio textus, y con ello realizar un ejercicio de cotejo seguro, confiable y libre de cualquier subjetividad propia del editor crítico, el cual servirá de guía para las sucesivas comparaciones de los testimonios seleccionados en esta importante etapa filológica de 
la collatio. El establecimiento del texto base es un paso fundamental en la aspiración de construir una edición crítica fiel a la voluntad del escritor, pues constituye la elección del testimonio sobre el que se tiene certeza que el escritor haya ejercido un efectivo control sobre él. Para Pérez Priego (2011), el texto base es el testimonio central del cotejo y su selección siempre será provisional y funcional, dado que "con frecuencia se acude al texto del mejor manuscrito o impreso conservado, o el más completo o más antiguo [...] o incluso el más autorizado" (p. 126). Por tanto, el testimonio más autorizado gozará de este reconocimiento y privilegio, el cual siempre será provisional hasta que se hallen nuevos testimonios que desvirtúen tal protagonismo. Sin embargo, en este caso concreto, hasta el momento no se cuenta con testimonios distintos a los relatos en este texto.

Como se ha evidenciado a lo largo de este artículo, todos los testimonios de El maestro de escuela se hallaron con facilidad en diferentes bases de datos, archivos o bibliotecas, lo que permite un acceso tranquilo y expedito a la tradición textual de la obra. Asimismo, se corroboró que en la historia de transmisión textual de la gran mayoría de las ediciones de la novela parten de la edición príncipe o primera de 1941 no solo por ser la más antigua, sino también por ser la más autorizada, dado que es la única edición que se publica en vida del escritor y en la que, seguramente, se pudo contar con intervención directa de Fernando González en el proceso de edición y publicación final. En este sentido, es fundamental el planteamiento de Fernando Colla (2005) cuando plantea que el criterio más válido para la selección del texto base pasa por que se tenga la certeza de que dicho testimonio "represente cabalmente la voluntad testamentaria del escritor, y que evidentemente éste haya ejercido un efectivo control sobre ella" (p. 184), situación que consideramos fundamental a la hora de la elección del texto base y que, para este caso concreto, se cree que el escritor participó directamente en el proceso de 1 edición príncipe de su obra.

Con base en lo anterior, y luego del estudio de transmisión de los testimonios de El maestro de escuela, se ha decidido que el texto base para el estudio del cotejo será la primera aparición de la obra en 1941 en la editorial bogotana ABC. Esta decisión no es arbitraria si se tiene en cuenta que es fácil advertir que dicho testimonio fue durante casi treinta años el único que sirvió de referencia para la lectura y recepción de la obra, así como de referente más próximo a las intenciones del escritor tanto en vida como posterior a su muerte. Además, ese testimonio se convirtió en la base de la segunda edición de la novela en 1970 por parte de la Editorial Bedout, que a la 
vez se constituyó en base de las sucesivas ediciones y reimpresiones de la novela. Es fundamental reiterar que este testimonio base no solo es el más antiguo y el único que se publicó en vida del escritor, sino que además está muy bien conservado y por ello mismo representa fielmente la voluntad del escritor.

Por último, la elección del testimonio de El maestro de escuela de 1941 como texto base o testimonio de colación se convierte en un insumo importante en este proceso de edición de textos con criterio filológico, dado que no siempre se logra acceder a él, lo que genera problemas en el proceso de la colación; en otras ocasiones resulta tan compleja tal identificación que el editor debe recurrir a la reconstrucción del texto base para poder obtener un texto fiable para el posterior ejercicio de la collatio. En suma, en este proceso filológico de la recensio se pudo contar con la definición del texto base, y esto se convierte en un insumo fundamental para la comprensión del fenómeno textual que se tiene como objeto de estudio.

\section{Consideraciones finales}

Para finalizar, se debe reiterar que el estudio de la recensio de El maestro de escuela del escritor colombiano Fernando González constituye el primer momento filológico para la construcción de una nueva edición de la novela, primera en edición crítica, y con ello la posibilidad de acceder a la tradición textual de la obra para garantizar la mejor edición del texto primigenio, atendiendo siempre a reivindicar el espíritu literario de su producción, y respetando los propósitos estéticos, culturales e ideológicos de su creador. De acuerdo con lo anterior, la elaboración de la edición crítica de esta importante novela posibilitará una nueva edición que enmiende las deficiencias halladas en el estudio de la recensio, así como en el posterior cotejo, con el objetivo de restituir la obra en su sentido originario para una mejor lectura y un mejor proceso de estudio crítico por parte de un público especializado.

El estudio filológico de una obra literaria permite la depuración de las posibles inconsistencias que hayan afectado su tradición textual, en este caso una tradición de ochenta años, y con ello procurar la integridad del texto primigenio para garantizar su conservación mediante procesos de corrección filológica y actualizaciones de categorías ortográficas, semánticas, sintácticas, tipográficas y pragmáticas, según lo ameriten las nuevas disposiciones editoriales que facilitan la lectura y la comprensión de la novela. Con este estudio se estimulan no solo las investigaciones de carácter filológico, sino también de carácter histórico, crítico o comparativo, toda vez que se pro- 
pician nuevas y fidedignas ediciones que conserven la intención original del escritor y generan nuevos públicos lectores que siempre garantizarán la vigencia de la obra, en este caso de la novela El maestro de escuela en nuestra tradición literaria nacional.

\section{Referencias bibliográficas}

Ardila Garzón, N. (2017). Semblanza de Editorial Norma (1960-2011). En Biblioteca Virtual Miguel de Cervantes - Portal Editores y Editoriales Iberoamericanos (siglos XIX-XXI) - EDI-RED. Recuperado de http://www.cervantesvirtual.com/obra/editorial-norma-1960-2011-semblanza-777435/ [30.01.2020]

Blecua, A. (2012). Estudios de critica textual. Madrid: Gredos.

Colla, F. (2005). Archivos. Cómo editar la literatura latinoamericana del siglo Xx. París: Centre de Recherches Latino-Américaines-Archivos.

Corporación Otraparte. (2002). Corporación Fernando González - Otraparte. Envigado. Recuperado de https://www.otraparte.org/casa-museo/historia-de-otraparte [26.02.2020]

Editorial Universidad de Antioquia (s.f.). Acerca de la Editorial. Medellín. Recuperado de http://www. udea.edu.co/wps/portal/udea/web/inicio/editorial/acerca-editorial [30.03.2020]

Fondo Editorial Universidad Eafit (s.f.a). Editorial Universidad Eafit. Medellín. Recuperado de http:// www.eafit.edu.co/cultura-eafit/fondo-editorial/presentacion/Paginas/presentacion-fondoeditorial.aspx [12.05.2020]

Fondo Editorial Universidad Eafit (s.f.b). Colección Biblioteca Fernando González. Medellín. Recuperado de http://www.eafit.edu.co/cultura-eafit/fondo-editorial/colecciones/Paginas/biblioteca-fernandogonzalez.aspx [21.06.2020]

González, F. (1941). El maestro de escuela. Bogotá: ABC.

González, F. (2007). "En el parque Berrío” y “Carta a don Guillermo Johnson”. Agenda Cultural Alma Mater 134, pp. 1-3.

González, F. (2011). “Vivo ya en la Huerta del Alemán”. Boletín No. 99 Otraparte. Envigado. Recuperado de https://www.otraparte.org/corporacion/boletin/20110218-bol-99/\#: :text=Cada\%20 \%C3\%A1rbol\%20que\%20siembro\%20es,la\%20gloria\%20a\%20mi\%20puerta [01.06.2020]

Pérez Priego, M. (2011). La edición de textos. Madrid: Síntesis.

Pineda Cupa, M. A. (2019). Editar en Colombia en el siglo XX: La Selección Samper Ortega de Literatura Colombiana (1928-1937). Bogotá: Ediciones Utadeo-Ediciones Uniandes.

Valencia, M. (s.f.). La edición en Colombia. España: Instituto Cervantes. Recuperado de https://bit. ly/36qdOxr [28.04.2020] 